\title{
ETIKA MENUNTUT ILMU DALAM QS. AL-KAHFI AYAT 60-82 REINTERPRETASI KISAH NABI MUSA DALAM UPAYAMENGHADAPI DEKADENSI MORAL PELAJAR
}

\author{
Mutaqin Al-Zamzami \\ Universitas Islam Negri Yogyakarta
}

\begin{abstract}
For moslems, al-Qur'an is a guide book for everything and its' content will always be relevant over times. Therefore, it is necessary to refer problems in educations to al-Qur'an with its interpretations, both classic and new interpretation. One of many problems in education is students' ethics in the process of education. So far, moral decadence is a main concern that yet to be solved. There are many violence against teachers that show us that morality issue is a major consideration in education. Based on this background, the writer observe that it is important to formulate an ethical basis that are inspired by islamic primary sources, alQur'an and al-Sunnah.
\end{abstract}

One of Quranic content that is relevant with this matter is Moses PBUH story in surah alKahfi verses 60-82, as one of the goals of al-Qashash (Quranic stories) is as lesson from the previous ummah. In addition, the verses clearly show the ethics of the Prophet Moses when studying with the Prophet Khidr, such as: being polite, accepting punishment, obedience etc. This work will use thematic analytical methods and see the verse general discussion of the Prophet Moses, in order to bring up new meanings of ethical values in these verses.

Keywords : Ethics, Qashash (Quranic Stories), Education, Khidir, Moses.

\begin{abstract}
Abstrak
Bagi umat Islam, al-Qur'an merupakan kitab petunjuk dalam segala urusan yang akan selalu sesuai dengan perkembangan zaman. Oleh karena itu, sudah sepatutnya permasalahan dalam dunia pendidikan di masa ini juga dirujuk kepada al-Qur'an baik dengan penafsiran klasik
\end{abstract}




\section{Mutaqin Al-Zamzami}

maupun dengan pemaknaan yang baru. Di antara permasalahan pendidikan tersebut adalah etika pelajar dalam menuntut ilmu. Hingga kini, dekadensi moral merupakan permasalahan pokok yang belum terselesaikan. Adanya kasus kekerasan terhadap guru menunjukkan bahwa moralitas adalah permasalahan fundamental dalam dunia pendidikan. Oleh karena itu, penulis memandang perlunya merumuskan suatu etika yang merujuk kepada sumber pokok ajaran Islam. Salah satu kandungan al-Qur'an yang dapat dijadikan rujukan dalam hal tersebut, yakni Cerita Nabi Musa dalam surat al-Kahfi ayat 60-82, karena salah satu dari tujuan al-Qashash fi al-Qur" an yakni sebagai bahan pembelajaran dari umat-umat terdahulu. Selain itu, ayat tersebut menunjukkan secara jelas bagaimana etika Nabi Musa ketika berguru kepada Nabi Khidir, seperti: bersikap sopan, menerima hukuman, taat dll. Karya ini akan diperdalam menggunakan metode analitis tematis serta melihat munasabah al-ayah yang membahas Nabi Musa, agar memunculkan makna baru tentang nilai etika dalam ayat-ayat tersebut.

\section{Keywords : Etika, Qashash al-Qur'an, Pendidikan, Khidir as, Musa as.}

\section{A. Pendahuluan}

Al-Qur'an merupakan Firman Allah Swt yang diturunkan kepada Nabi Muhammad Saw dan para umatnya. Bagi umat Islam, al-Qur'an diyakini sebagai petunjuk bagi manusia, seperti termaktub dalam surat al-Baqarah ayat 185. Al-Qur'an diturunkan sejak abad ke-7 M dan sejak saat itu pula, masyarakat muslim mulai berinteraksi dengan al-Qur'an sampai saat ini.

Pada abad ke-21, begitu banyak permasalahan yang muncul dari berbagai bidang, di antaranya dalam dunia pendidikan yaitu masalah moralitas pelajar. Hal ini dibuktikan dengan tingginya angka kekerasan yang terjadi di ranah pendidikan Indonesia. Misalnya seperti yang tercatat oleh Federasi Serikat Guru Indonesia (FSGI), terdapat kekerasan yang melibatkan murid dengan temannya sendiri di Sukabumi. Siswa kelas 3 SD bernama SR (9 tahun) tewas setelah terlibat perkelahian dengan temannya di belakang sekolah (Kompas: 2017). Yang menyedihkan, terdapat juga kasus kekerasan yang melibatkan murid dengan guru yakni kasus penganiayaan terhadap guru oleh muridnya sendiri. Kejadian di daerah Sampang ini mengakibatkan tewasnya sang guru (CNN, 2018).

Fenomena keekerasan ini sangat bertolak belakang dengan ajaran Islam yang terkandung dalam al-Qur'an. Misalnya jika kita merujuk kedalam cerita Nabi Musa dan Nabi Khidir dalam Surat al-Kahfi. Dalam cerita tersebut, dapat kita simpulkan sikap ketawadhu'an serta 
integritas seorang murid dalam usaha memperoleh ilmu.

Persoalan etika dalam pendidikan juga banyak dibahas oleh para ulama muslim, misalnya Ibnu Qayyim al-Jauzi, Ibnu Taimiyah, Muhammad Abduh, Murtadha Mutahhari serta Sayyed Hossein Nasr (Iqbal, 2015:353). Menurut Sayyed Hossein Nasr (2015), pendidikan menurut perspektif Islam bukan sekedar pengajaran atau penyampaian materi (ta'lim), tetapi juga pelatihan seluruh diri siswa (tarbiyah). Oleh karena itu, guru bukan sekedar seorang muallim (penyampai pengetahuan) tetapi juga seorang murabbi, pelatih jiwa dan kepribadian. Konsep tarbiyah ini berimplikasi pendidikan harus memperhatikan juga persoalan etika, bagaimana seorang murid bersikap terhadap gurunya, terhadap pelajaran, terhadap sesama murid, dll.

Dari berbagai macam permasalahan moral pelajar, pendidikan yang berlandaskan pada al-Qur'an sangatlah dibutuhkan dalam proses menghadapi tantangan modernitas. Ditinjau dari aspek filosofis, nilai yang terkandung dalam al-Qur'an, menurut Husain Munawar, tidak dapat dipisahkan dengan masalah etika (2005: xiii). Bagitu juga dalam ranah keindonesiaan, tujuan pendidikan yang tertulis dalam UU Pendidikan Nasional, seperti dikutip Sujiarto sejatinya mengandung misi pendidikan moral dan watak (2009:89). Maka penarikan Nilai-nilai etika dalam al-Qur'an adalah sebuah keniscayaan terutama dalam upaya menumbuhkan semangat Qur'ani dalam pendidikan Nasional. Al-Qur'an telah menyinggung hal ini, terutama dalam cerita rihlah Nabi Musa dengan Nabi Khidir, karena pada dasarnya cerita-cerita dalam alQur'an bukan hanya sebagai penghias kalam Tuhan, namun juga sebagai ibrah (teladan) yang dapat dijadikan panduan dalam hidup manusia.

\section{B. Kajian Pustaka}

Dalam buku berjudul Pemikiran Pedidikan Islam, yang ditulis oleh Abu Muhammad Iqbal, dijelaskan beberapa konsep pendidikan yang dicetuskan oleh para pemikir Islam, seperti Ibnu Sina, Ibnu Khaldun, Ibnu Taimiyah, Fazlur Rahman, Sayyed Hossein Nasr, dll. Pemikiran Sayyed Hossein Nasr secara khusus terdapat dalam bukunya yang berjudul Islamic Life and Thought. Buku ini secara umum membahas bagaimana Islam itu dimaknai dan diimplikasikan dalam kehidupan secara nyata dan di sisi lain dijadikan model pemikiran, termasuk dalam dunia pendidikan.

Sementara itu, pembahasan tentang konsep Islam tentang pendidikan beserta nilainilai edukasi dalam al-Qur'an dapat dirujuk kepada artikel Ali Mudhofir dengan judul Tafsir 


\section{Mutaqin Al-Zamzami}

Tarbawi sebagai Paradigma Qur'ani dalam Reformulasi Pendidikan Islam. Dalam kaitannya dengan cerita qashash al-Qur'an, penulis merujuk karya M. Faisol yang berjudul Struktur NaratifCerita Nabi Khidir dalam Al-Qur"an. Tulisan ini mengkaji struktur naratif cerita Nabi Khidir dalam al-Qur'an. Analisis terhadap struktur naratif cerita tersebut menjukkan adanya aspek penguatan keimanan kepada Allah. Namun, dalam tulisan ini kurang menekankan aspek linguistik serta sosio-historis yang melatar-belakangi cerita tersebut. Pembahasan tentang latar belakang linguistik akan kita temukan dalam karya Ella Elsis dkk. dengan judul Alih Aksara dan Alih Bahasa Teks Kisah Nabi Musa as dalam Naskah Teks Cerita Nabi-Nabi Versi Azhari al-Khalidi Rahmatullah. Tulisan ini membahas ceita Nabi Musa serta Nabi-nabi yang lain menurut Azhari al-Khalidi Rahmatullah, serta menjelaskan perubahan kebahasaan dari cerita tersebut. Artikel karya Novita Siswayanti berjudul Dimensi Edukatifpada Kisah-kisah al-Qur"an, diterbitkan dalam Jurnal Shuhuf vol.3, No. 1, 2010, menjelaskan, bahwa kisah dalam al-Qur'an bukan hanya sekedar menjelaskan suatu kejadian maupun informasi hidup seseorang. Namun, cerita-cerita yang ada kaya akan nilai-nilai edukasi. Menyangkut metode serta materimateri pembelajaran. Berangkat dari hal ini penulis melihat banyaknya nilai pendidikan yang bisa diangkat dalam cerita al-Qur'an namun penelitian yang terdahulu belum memberikan gambaran yang bersifat kontekstual serta mengorelasikannya dengan pemikir Islam kontemporer, hal ini yang menjadi penawaran baru dalam penelitian penulis.

\section{Metode Penelitian}

Jenis penelitian ini adalah penelitian pustaka (library research) dengan fokus pada makna yang terkandung dalam surat al-Kahfi ayat 60-82. Sumber data yang digunakan secara garis besar penulis bagi menjadi dua, yaitu sumber primer berupa kitab-kitab tafsir klasik maupun kontemporer serta sumber sekunder berupa kajian-kajian yang relevan dengan objek kajian. Teknik yang penulis gunakan adalah konten analisis dengan metode analitis tematis dalam rangka menemukan nilai-nilai pendidikan dalam cerita Nabi Musa. Karena cerita tersebut terdiri dari 22 ayat, maka tulisan ini lebib berfokus kepada substansi pendidikan moral atau etika yang terkandung dalam cerita tersebut, dengan penjelasan yang ringkas tanpa menjelaskan panjang lebar kronologi secara rinci dari setiap peristiwa yang ada. Sedangkan dalam penafsiran akan ditonjolkan interaksi antara Nabi Musa kepada Nabi Khidir, namun tidak menafikan sisi-sisi linguistik serta sosio-historis. 


\section{Pembahasan}

\section{Etika dalam perspektif al-Qur'an}

Etika merupakan sebuah istilah yang berasal dari bahasa Yunani kuno. Bentuk tunggalnya, ethos, mempunyai banyak arti di antaranya: kebiasaan, adat, akhlak, watak, perasaan, sikap, dan cara berpikir. Bentuk jamaknya ialah ta etha diartikan sebagai adat kebiasaan (K.Bertens, 2002: 14).

Sementara itu, secara terminologi, etika menurut Magnis Suseno merupakan bentuk usaha manusia untuk memakai akal budi dan daya fikirnya untuk memecahkan masalah bagaimana ia harus hidup kalau ia mau menjadi baik (1987: 17-18).

Dalam perspektif Islam, ukuran etis (kebaikan dan keburukan) bersifat mutlak, yaitu berdasarkan pedoman dalil al-Qur'an dan hadits Nabi Muhammad Saw. Maka, etika Islam dapat dikatakann merupakan sebuah doktrin etis yang berdasarkan dengan ajaran-ajaran agama yang ajaran primernya diambil dari al-Qur'an dan sunnah yang di dalamnya terdapat nilai-nilai terpuji (mahmudah) seperti: berlaku jujur (shidq), berbuat baik kepada kedua orang tua (birru al-walidain), memelihara kesucian diri (al-iffah), dan lain sebagainya.

Hamzah Yaqub menyebut etika Islam sebagai etika teologis (1990: 41), sementara Majid Fakhry menyebut etika berdasarkan dengan ajaran agama dengan istilah etika religious (1996: 68). Jika etika teologis adalah nilai-nilai baku yang merujuk kepada sumber agama, maka etika religius berakar dengan spirit dan ketentuan yang terdapat di dalam al-Qur'an dan sunnah dengan memusatkan pada usaha untuk mengeluarkan moralitas Islam dengan cara langsung.

\section{Etika Murid terhadap Guru dalam Surat Al-Kahfi 60-82}

Dari kisah Nabi Musa As dan Nabi Khidir As yang diceritakan dalam al-Qur'an pada Surat al-Kahfi ayat 60-82, penulis menyimpulkan beberapa kode etik yang dapat digunakan ketika berinteraksi dengan guru, yakni:

1) Murid harus mempunyai semangat yang tinggi dan tidak putus asa dalam mencari ilmu, meski jarak yang ditempuh jauh dan membutuhkan waktu yang lama. Ini adalah nilai yang terkandung dalam surat al-Kahfi ayat 60-64 yang menceritakan perjuangan Nabi Musa As untuk mencari Nabi Khidir As. Dalam tafsir al-Thabary dikisahkan bahwa Nabi Musa 


\section{Mutaqin Al-Zamzami}

As meminta Yusya' bin Nun yang menjadi rekan perjalanan untuk membawakan makanan untuknya, karena benar-benar lelah usai menjalani perjalanan jauh dalam mencari Nabi Khidir As (al-Thabary: 127).

2) Seorang murid harus bersikap sopan kepada gurunya, dalam cerita tersebut tergambarkan ketika Nabi Musa meminta izin untuk mengikuti (baca: belajar) kepada Nabi Khidir As.

Menurut al-Thabary kata 'abdan min 'ibadina pada ayat 65 merujuk kepada Nabi Khidir As. Ayat selanjutnya menceritakan bagaimana Musa As kemudian mendatangi khidir seraya mengatakan keinginannya untuk berguru kepada Nabi Khidir (Al-Thabary: 1163).

"Musa berkata kepada Khidir, 'Bolehkah aku mengikutimu?',

3) Berbaik-sangka dan meyakini bahwa guru lebih pandai dari murid. Dengan melakukan hal ini akan muncul sifat ketawadu'an kepada guru serta dengan sendirinya akan menghilangkan sifat sombong. Nilai tersebut diisyaratkan dalam frasa mimma ullimta rusydan (di antara ilmu-ilmu yang telah diajarkan kepadamu). Ini selaras dengan filosofi gelas kosong. Kesombongan pelajar ibarat gelas yang merasa penuh sehingga tidak akan dapat diisi lagi tambahan ilmu dari gurunya.

4) Murid tidak selayaknya mudah merasa tersinggung, tatkala guru melemahkan/ merendahkan murid dengan perkataannya.

"Musa berkata: 'Insya Allah kamu akan mendapati aku sebagai orang yang sabar, dan aku tidak akan menentangmu dalam sesuatu urusanpun.” (Al-Kahfi: 69). Ayat tersebut merupakan respon dari perkataan Nabi Khidir As yang telah melemahkan Nabi Musa As dengan perkataan: "Sesungguhnya kamu sekali-kali tidak akan sanggup sabar bersama aku. Dan bagaimana kamu dapat sabar atas sesuatu, yang kamu belum mempunyai pengetahuan yang cukup tentang hal itu? (Al-Kahfi: 67-68). Dalam ayat 68, dapat kita simpulkan bahwa ketika guru melakukan sesuatu yang terlihat seperti melemahkan/merendahkan seorang murid, sesungguhnya hal itu disebabkan oleh keadaan guru yang lebih mengetahui suatu perkara dibandingkan muridnya. Jadi, terkadang logika murid tidak mampu menangkap rasionalitas tindakan seorang guru. Di sisi lain, ayat ini dapat dimaknai sebagai sebuah motivasi Nabi Musa As untuk lebih bersabar/lebih giat dalam belajar agar dapat memahami perkataan/tindakan gurunya. 
6) Mempunyai komitmen untuk menjalankan perintah guru.

Musa berkata: "InsyaAllah kamu akan mendapati aku sebagai orang yang sabar, dan aku tidak akan menentangmu dalam sesuatu urusanpun.” (Al-Kahfi: 69).

Ayat ini merupakan jawaban Musa As terhadap pernyataan Khidir As bahwa Musa As tidak akan pernah dapat sabar terhadapnya dikarenakan ketidaktahuan Musa As. Akan tetapi, komitmen untuk bersabar telah dinyatakan Musa As dari awal kebersamaannya dengan gurunya (Khidir As).

7) Bertanya kepada guru sesuai dengan izin dan kondisi sang guru.

Dia berkata: "Jika kamu mengikutiku, maka janganlah kamu menanyakan kepadaku tentang sesuatu apapun, sampai aku sendiri menerangkannya kepadamu.”(Al-Kahfi:70).

8) Adanya penyesalan dan permintaan maaf kepada guru, ketika murid melakukan kesalahan.

Musa berkata: "Janganlah kamu menghukum aku karena kelupaanku dan janganlah kamu membebani aku dengan sesuatu kesulitan dalam urusanku.” (Al-Kahfi:73).

9) Seorang murid harus siap menerima konsekuensi atas pelanggaran yang dilakukan.

Khidhr berkata: "Inilah perpisahan antara aku dengan kamu; kelak akan kuberitahukan kepadamu tujuan perbuatan-perbuatan yang kamu tidak dapat sabar terhadapnya. (AlKahfi: 78).

Poin-poin di atas menunjukkan nilai-nilai penghormatan murid kepada guru. Oleh karena itu, penulis akan menjelaskannya sedikit-banyak terkait permasalahan etika murid terhadap guru.

\section{Reinterpretasi Nilai Penghormatan kepada Guru dalam Konteks Kekinian}

Kisah Nabi Musa As dan Nabi Khidir As dalam surat al-Kahfi ayat 60-82 tidak secara langsung dapat ditafsirkan dalam konteks penafsiran tarbawi (pendidikan). Akan tetapi, ayat- 


\section{Mutaqin Al-Zamzami}

ayat tersebut mengandung nilai-nilai yang penting dalam pendidikan, yakni penghormatan tinggi yang dilakukan Nabi Musa As sebagai murid kepada Nabi Khidir As sebagai sang guru. Nilai tersebut dapat kita simpulkan dari permintaan/permohonan izin Nabi Musa As kepada Nabi Khidir As untuk berguru kepadanya, komitmen dalam menaati perintahnya, permintaan maaf setelah melakukan kesalahan, dan lain-lain yang telah penulis paparkan di atas. Jika cerita Nabi Musa As tersebut dilihat dengan cerita kehidupan Nabi Musa As yang lain dalam al-Qur'an, akan kita temukan nilai-nilai pendidikan lain.

Nabi Musa dilukiskan sebagai Nabi yang ketika bayi dihanyutkan ke sungai untuk menghindari kekejaman Fir'aun. Al-Qur'an tidak menyinggung secara jelas sosok kedua orang tuanya, terutama ayahnya, namun disebutkan bahwa Nabi Khidir merupakan guru dari Nabi Musa.

Jika mendadabburi al-Qur'an, akan kita temukan bahwa tugas mendidik anak merupakan tanggungjawab orang tua (Al-Tahrim: 6), atau kerabat terdekatnya (Al-Syu'ara: 214) (Eko Prasetyo, 2012: 119). Di dalam ayat yang lain, al-Qur'an menyatakan bahwa anak adalah al- 'aduw (musuh) (al-Taghabun: 14). Peringatan al-Qur'an tentang kehadiran anak sebagai musuh menunjukkan bahwa anak sesungguhnya tidak bisa dianggap sebagai hasil hubungan biologis suami istri semata. Orang tua harus memberikan hak dan kewajiban kepada anak, begitu pula sebaliknya. Apabila kedua belah pihak mendapatkan hak dan kewajibannya maka tidak akan permusuhan (Izzan dan Salehuddin, 2012: 210-213).

Salah satu kewajiban orang tua yakni mendidik anaknya, tugas tersebut biasanya dialihkan kepada guru sebagai pendidik di lembaga pendidikan. Menurut Nasr, guru adalah murabbi (pendidik), yang menjadikannya berkedudukan lebih tinggi daripada hanya seorang $\mathrm{Mu}$ "allim (pengajar) (1994: 150). Dalam bahasa arab guru disebutkan dengan istilah mu'allim, murabbi, mudarris, dan mu'addib. Keempat terma tersebut, memiliki makna subtil yang berbeda-beda.

Pertama, mu'allim berasal dari kata 'allama, secara istilah diartikan kepada penggambaran seseorang (guru) yang mempunyai kompetensi keilmuan yang sangat luas. Kedua, murabbi berasal dari kata raba-yarbu, yang berarti: bertambah dan bertumbuh. Maka guru sebagai murabbi berarti mempunyai perana dan fungsi membuat pertumbuhan, perkembangan, serta menyuburkan intelektual dan jiwa peserta didik. Ketiga, mudarris yang berasal dari kata darasa yang berarti: meninggalkan bekas. Maka guru sebagai mudarris mempunyai tugas dan kewajiban membuat bekas dalam jiwa peserta didik. Bekas itu 
merupakan hasil pembelajaran yang berwujud perubahan perilaku, sikap, dan penambahan atau pengembangan ilmu pengetahuan mereka. Keempat, mu'addib merupakan isim faildari kata addaba yang berarti sopan. Maka guru sebagai mu'addib mempunyai tugas membuat anak didiknya menjadi insan yang berakhlak mulia sehingga mereka berperilaku terpuji (M. Yusuf, 2013: 62-64).

Penjelasan di atas menunjukkan bahwa guru juga menyandang tugas orang tua dalam mendidik intelektual serta jiwa anak. Maka, hal ini akan mempengaruhi etika yang harus dikedepankan seorang murid kepada berhadapan/berinteraksi dengan gurunya. Mengutip pendapat Syaikh al-Zarnuji, bahwa guru adalah bapak. Pendapat ini memberi konsekuensi terhadap perasaan dan sikap guru yang memanifestasikan cita-cita orang tua murid. Posisi ini, harus disadari oleh kedua belah pihak, sehingga terwujud keseimbangan dalam hak dan kewajiban yang tercermin dalam sikap pribadi masing-masing, baik guru maupun murid. Hubungan ini menunjukkan kedekatan dari sisi psikologis (Ibrahim: 36).

Posisi ini dipertegas oleh Syaikh az-Zarnuji, bahwa sesungguhnya guru yang mengajar seorang murid walaupun satu huruf dalam hal agama, maka dihukumi sebagai bapak dalam agama, "Maka sesungguhnya orang yang mengajarkanmu satu huruf yang hal tersebut berhubungan dengan masalah agama dan hal itu kamu perlukan, maka ia (guru) tersebut, dapat dihukumi sebagai bapakmu dalam agama." (Ibrahim: 17).

Dari penjelasan tersebut, menunjukkan bahwa hubungan orang tua dan anak tidak terbatas hubungan biologis. Guru sebagai pendidik anak, dapat diposisikan sebagai pengganti tugas orang tua dalam mendidik anak. Maka implikasinya, seorang anak harus menjadikan guru sebagai manifestasi orang tua. dan tentunya bersikap ta'at dan mengikuti aturan-aturan yang telah dijelaskan dalam al-Qur'an:

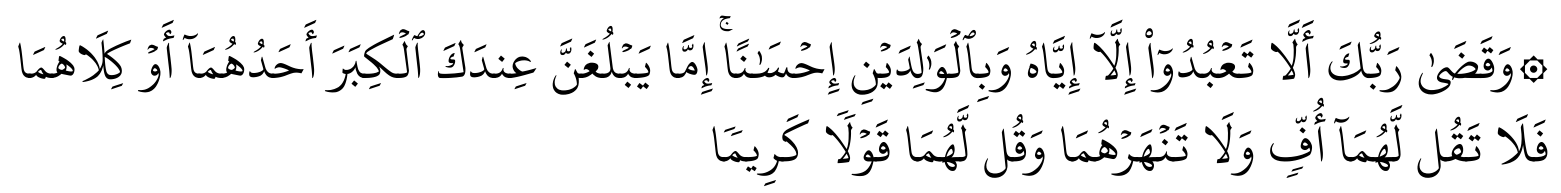

Artinya: "Dan Tuhanmu telah memerintahkan supaya kamu jangan menyembah selain Dia dan hendaklah kamu berbuat baik pada ibu bapakmu dengan sebaik-baiknya. Jika salah seorang di antara keduanya atau kedua-duanya sampai berumur lanjut dalam pemeliharaanmu, maka 


\section{Mutaqin Al-Zamzami}

sekali-kali janganlah kamu mengatakan kepada keduanya perkataan "ah" dan janganlah kamu membentak mereka dan ucapkanlah kepada mereka perkataan yang mulia.” (QS. AlIsra': 23).

Ayat ini membahas tentang etika kepada orang tua. Jika mengikuti pendapat Zarnuji di atas, bahwa posisi guru tak beda dengan status orang tua. Maka, penghormatan kepada guru, secara konkrit dapat dirujuk kepada ayat ini. Seperti halnya perkataan keras tidak boleh dikatakan kepada orang tua, maka demikian pula halnya kepada seorang guru. Lebih dari itu murid tidak boleh mencaci atau memukuli sosok yang menggantikan tugas orang tua sebagai pendidik anak.

Maka dapat disimpulkan, bahwa salah satu cara untuk dapat menghormati guru, yakni dengan memposisikannya sebagaimana orang tua, dan memanifestikan norma-norma kepatuhan dan keta'atan sebagaimana kerika berinteraksi dengan orang tua kandung.

\section{E. Penutup}

Etika merupakan sebuah istilah yang dapat merujuk kepada kebiasaan, adat, akhlak, watak, perasaan, sikap, dan cara berpikir. Sedangkan etika pendidikan berarti nilai-nilai moral (akhlak) yang digunakan ketika dalam proses menuntut ilmu termasuk di dalamnya ketika melakukan interaksi kepada pendidik.

Secara ringkas Nilai-nilai etika yang terkandung dalam QS. Al-Kahfi,ayat 60-82 dapat dirumuskan sebagai berikut:

1) Murid harus mempunyai semangat yang tinggi dan tidak putus asa dalam mencari ilmu, meski jarak yang ditempuh jauh dan membutuhkan waktu yang lama.

2) Seorang murid harus bersikap sopan kepada gurunya.

3) Meminta arahan dalam menuntut ilmu, terutama terkait ilmu-ilmu yang belum dipelajari.

4) Berbaik-sangka dan meyakini bahwa guru lebih pandai dari murid. Murid tidak 
selayaknya mudah merasa tersinggung, tatkala guru melemahkannya dengan perkataannya.

5) Tidak mudah merasa tersinggung, tatkala guru melemahkannya dengan perkataannya.

6) Mempunyai komitmen untuk menjalankan perintah guru atau bersikap taat.

7) Bertanya kepada guru sesuai dengan izin dan kondisi dari seorang guru.

8) Adanya penyesalan dan permintaan maaf kepada guru, ketika murid melakukan kesalahan.

9) Seorang murid harus siap menerima konsekuensi atas pelanggaran yang dilakukan.

Kemudian, bentuk penghormatan kepada guru,dapat disejajarkan dengan kode etik alQur'an yang membahas tentang perhormatan kepada orang tua pada surat al-Isra' ayat 23. 


\section{Mutaqin Al-Zamzami}

\section{DAFTAR PUSTAKA}

Ahmad Izzan dan Salehuddin. 2012. Tafsir Pendidikan: Studi ayat-ayat berdimensi pendidikan. Jakarta: Pustaka Aufa Press.

Fakhry, Majid. 1996. Etika dalam Islam. Yogyakart: Pustaka Pelajar.

Ibrahim bin Isma'il, Syarah Ta"lim Mutaallim. Semarang: Pustaka Alawiyah.

Iqbal, Abu Muhammad. 2015. Pemikiran Pendidikan Islam. Yogyakarta: Pustaka Pelajar.

K. Bertens. 2002. Etika. Jakarta: Gramedia Pustaka Utama.

Khalidy, Shalah al-. 2000. Kisah-kisah al-Qur"an "pelajaran dari orang-orang terdahulu”, jilid II. Jakarta: Gema Insani.

Khalafallah, Muhammad Ahmad. 1951. al-Fann al-Qashasi fi al-Qur"an al-Karim. Kairo: Maktabah an-Nahdah al-Misyriyah.

Yusuf, Kadar M. 2013. Tafsir Tarbawi "Pesan-pesan al-Qur"an tentang Pendidikan”. Jakarta: Amzah.

Suseno, Franz Magnis. 1987. Etika Dasar: Masalah-masalah Pokok Filsafat Moral. Jakarta: Kanisius.

Nasr, Sayyed Hossein (dkk). 2015. The Study Quran A New Translation and Commentary. New York: HarperOne.

Nasr, Sayyed Hossein. 1994. Islam Tradisi di Kancah Dunia Modern, terj, Lukman Hakim. Bandung: Pustaka.

Al-Thabari, Ibn Jarir. "Jami’ul Bayan an Tawilil Ayatil Qur"an.” Jilid 5. Cet.I. Beirut: Muassasatul Risalah.

Estu Suryowati (26 Desember 2017). Federasi Serikat Guru: 2017, Kekerasan di Dunia Pendidikan Makin Masif. Diakses pada 15 September 2018. https://nasional.kompas. $\mathrm{com} / \mathrm{read} / 2017 / 12 / 26 / 17513181 /$ federasi-serikat-guru-2017-kekerasan-di-duniapendidikan-makin-masif.

CNN Indonesia (2 Februari 2018. PGRI Minta Polisi Usut Tuntas Pembunuhan Guru di Sampang. CNN Indonesia (online). Diakses pada 15 September 2018. https://www. cnnindonesia.com/nasional/20180202142615-12-273415/pgri-minta-polisi-usut-tuntas-pembunuhan-guru-di-sampang 